\title{
Least Interference channel allocation algorithm in composite networks with FEMTOCELL by using SFAB
}

\author{
${ }^{1}$ Venkata Vara Prasad Padyala, ${ }^{2}$ Dr. K. V. D. Kiran \\ ${ }^{1}$ Department of Computer Science Engineering, Koneru Lakshmaiah Education Foundation, India varaprasad_cse@kluniversity.in \\ ${ }^{2}$ Department of Computer Science Engineering, Koneru Lakshmaiah Education Foundation, India kiran_cse@kluniversity.in
}

\begin{abstract}
In present communication world the entire communication is functioning as wireless, the communication will be happened with the mobile devices or any user equipment (UE) which will connect to the internet by the cellular base station by using a channel. The cellular communication unable to provide signal coverage to entire region which is covered by Base Transceiver Station (BTS). So femtocell came in to picture to provide signal to uncovered region also. The main problem is the channel allocation to the newly entered UE in to the femtocell from marco cell. The newly proposed algorithm which is working based on spectrum fragmented agile broadcast (SFAB) method to allocate the channel to the UE. This approach will reduce the interference between channels, Quality of Service (QOS) will increase, call blocking is reduced and call dropping is reduced.
\end{abstract}

Key words: Base Transceiver Station, spectrum fragmented agile broadcast, composite network, FEMTOCELL, handoff.

\section{INTRODUCTION}

The drastic developments in the wireless mobile communication, it leads to increase the number of users. The mobile devices are used by more number of people and they are moving from one place to another place, but the majority times they at working place or leaving places. With this we can estimate that $80 \%$ mobile traffic in indoor places ${ }^{[1]}$. To maintain the overloaded traffic in macro cells and enhance the capacity of wireless network, the distance between the Base Transceiver Station (BTS) to be decreased. So establishing those many BTS is more difficult and cost effective. Instead of BTS the Femtocell can be used to cover the each and every cell region. Assigning channel to the users in Femtocell is an important research area ${ }^{[2]}$.

Femtocell is like a small BTS used to enhance the coverage area of indoor places. The establishment of femtocell is very simple and it's movable. The communication mechanism to femtocell will be provided by the network operator and the connection can be done with optical fiber or Digital Subscriber Line (DSL) ${ }^{[3]}$. By having femtocell in the cellular network the entire architecture can be divided as macrocell tier and femtocell tier. With this two tier models the channel interference can be happened it leads to reduce the quality of experience (QOE) of communication. To avoid the interference problem previous solutions are maiming the distance between the cell regions with the formula $\mathrm{D}=\sqrt{3 N}$ $\mathrm{R}$. where $\mathrm{D}$ indicated the distance between cells, $\mathrm{R}$ is radius of coverage area radius and $\mathrm{N}$ number of BTS. But in each region based on requirement the femtocell can be placed, due to this interference problem may come as mentioned above.

To avoid this problem new channel allocation mechanism be introduced.

The above cellular architecture of macro cell and femto cell leads to the cross tier architecture of communication. When a user in femtocell region using the channel may lead to interference with the macro cell region, to avoid this Orthogonal Frequency Division Multiple Access (OFDMA) approach was given to reduce the handover and interference problem ${ }^{[3]}$. This will solve the closed sub scriber Group (CSG) problems with approach of OFDMA method. So the open and closed access can be done without any interference. Sudden increase in the channel usage can be addressed with the method Dynamic Channel Allocation (DCA), which cannot be solved by the Fixed Channel Allocation (FCA). The OFDMA can solve the channel interference with FCA by using the carrier channels but the sudden demand for channels with dynamic increase of users or usage of channels can be addressed with DCA method by having threshold values while assigning the channels to user ${ }^{[4]}$.

The limited spectrum availability can lead to NP-hard problem for channel allocation in cellular mobile communication. So the FCA and DCA also will not give the exact optimal solution due to limited spectrum availability. With the Hybrid Channel Allocation the problem can be solved by including the Genetic Algorithm for channel allocation based on demand for channel allocation. If no demand then the general FCA method can be used for channel allocation. If demand is there then DCA optimization with GA can be used for channel allocation ${ }^{[5]}$. But with this the call blocking problem was not addressed.

The access can be classified in to open access, closed access and hybrid access. In open access communication the devices 
available in cellular region can access without any restrictions, newly entered devices can also access the communication channels of the cellular region under particular BTS. In closed access communication it's very restricted to particular users, only specified users can access the channels available in the cellular region under the BTS. But now days the communications are like hybrid access communication any user can go to other regions can that region channels can be used with cognitive features. --users in the Femtocell will be divided in to two categories as 1 . Subscriber Group (SG) 2. Non Subscriber Group (NSG). Here the cognitive principle will be applied to access the primary user channel by the secondary user. While accessing the SG channels by the NSG the channel interference can be happened, so it should be addressed. The SG those who are using the primary channels, if these SG is not using the channels the NSG group can access it by applying the cognitive feature. While in this process the SG user equipment should not suffer with the call blocking problem, it should be addressed. And the quality of service (QOS) should be maintained in such a way the user should get quality of experience (QOE). All these can be solved by the channel allocation process.

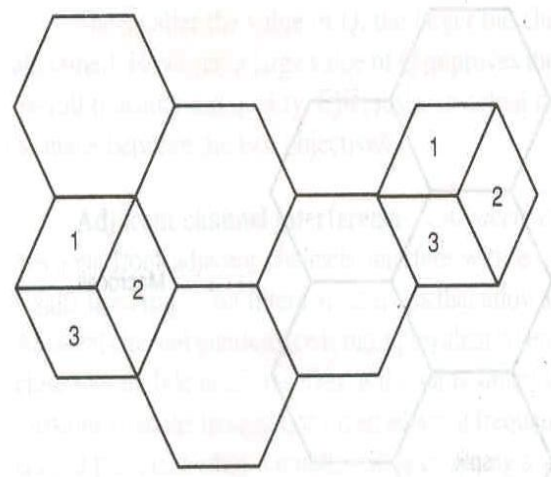

Figure 1 :Sectoring of Hexagonal cellular regions

In general cellular mobile communication the entire region will be divided in to cellular region of hexagonal shape, with this entire area will be covered. Still farther it can be divided in to sub parts. Based on the antenna properties and the coverage signal region each cell region can be divide it to 120-degree sector ${ }^{[6]}$. In above fig. 1 sectoring of hexagonal cellular is divided in to three parts and covered with 120 degree directional antennas. In this scenario the handoff/handover comes in such a way that a mobile equipment (ME) moving from one region of cellular region to other cellular region then it will disconnect from the first region and establishing connection with the second region coverage part, then call dropping or call disconnection to be avoided this can be achieved with hand off/ handover mechanisms. The main point here is how the channel allocation will be done in sectoring level.

Augmented Channel allocation Matrix (ACAM) is going to maintain all channels which are allocated to the user equipment and it contains the free channels available in the cellular region. If any change in the channel allocation the ACA table will inform to all base station regions which are interconnected in the cellular region. If any natural calamity occurs then the FCA in the cellular region will not work then the DCA to be applied. Nowadays the channel allocation using both the FCA and DCA it's called as Hybrid Channel Allocation (HCA). ACAM is showing the channel allocation and occupancy numbers at each iteration. Based on this channel allocation will be done in the cellular region ${ }^{[7][8]}$. But the sector in each cellular region was not addressed. The sectoring came in to picture with directional antennas gives the signal strength in particular direction and the FEMTOCELL antennas which gives signal coverage in the uncovered region of main Base transceiver station. In same cellular region channel allocation for a particular sector region, to the device $\mathrm{UE}$ which is moving from one region to another region addressed in section II. New HCA algorithm with SFAB is addressed in section III. Finally how our proposed method is best compared to remaining channel allocation algorithms is in conclusion part section IV.

\section{SYSTEM DESCRIPTION}

If cellular region each cell further divided into small regions and it can be covered by the directional antennas or femto cell which cover the entire region. Fig.2 is showing about the cellular system having the base station and femtocell. Channel allocation can be done with the MAC layer in such a way that highest reliable and robust interference free allocated channel to be provided. Each FEMTOCELL will be covered or providing signals by the macro cell i.e. Base Station. The Cognitive Radio based mechanism uses the subcarrier weight values to avoid the collision between the base station users and the FEMTO users but with this approach the signal to noise ratio was not able to control ${ }^{[9]}$.

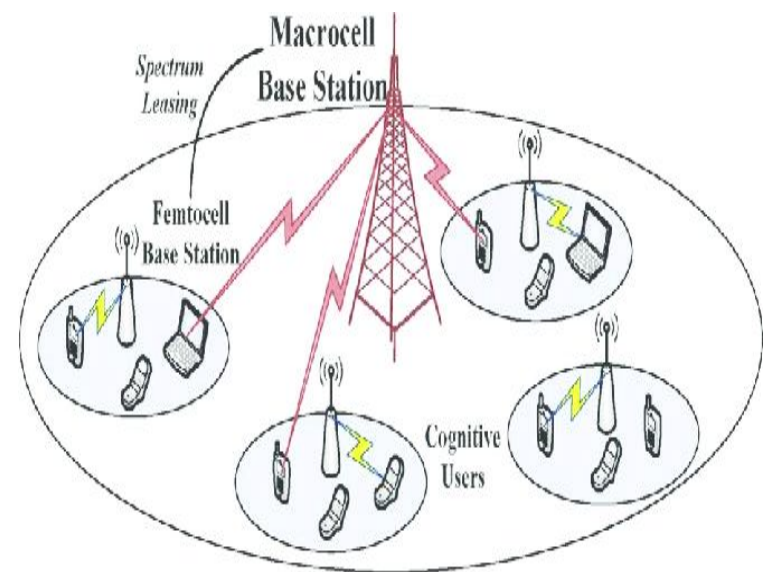

Figure 2: Cellular System architecture with macro cell Base Station and FEMTO CELL

With cognitive weight principles finding the primary channels which are free is very difficult. Even with the weight values or time slots of channels allocated to primary user is identified but with in less time the channel to be released by 
the FEMTO user to primary user because of demand from the primary user and more noise value also there ${ }^{[10]}$. With these approaches finding the channel from the macro base station is very difficult so we need iterative and incremental model to find the best channel for communication for FEMTO user. Finally an agile model was designed in such a way that by applying the distributed random variable on the channels list which are free i.e. not used by the primary users under the macro base station region ${ }^{[11]}$.

Choose the subset $I=\{1,2,3, \ldots \ldots n\}$ channels for communication, among all these unused channels can be identified by using the carrier sensing algorithms like CSMA. The unused channels we call as empty set which is denoted as $\phi n$.

Table 1: Augmented Channel allocation Matrix

\begin{tabular}{|c|c|c|c|c|c|c|c|c|c|}
\hline Base & \multicolumn{7}{|c|}{ Channel Number } & \multicolumn{1}{c|}{} \\
\cline { 2 - 8 } $\begin{array}{c}\text { Station } \\
\text { State }\end{array}$ & 1 & 2 & 3 & 4 & 5 & 6 & $\ldots$ & $\mathrm{n}$ & $\begin{array}{c}\text { Allocate } \\
\text { channel }\end{array}$ \\
\hline $\mathrm{I}_{1}$ & $\mathrm{X}$ & & $\mathrm{X}$ & & & $\mathrm{X}$ & & $\mathrm{X}$ & 2 \\
\hline $\mathrm{I}_{2}$ & & $\mathrm{X}$ & $\mathrm{X}$ & & $\mathrm{X}$ & $\mathrm{X}$ & & $\mathrm{X}$ & 1 \\
\hline $\mathrm{I}_{3}$ & $\mathrm{X}$ & & & $\mathrm{X}$ & & & & & 2 \\
\hline$\ldots$ & & & & & & & & & \\
\hline $\mathrm{I}_{\mathrm{n}}$ & $\mathrm{X}$ & $\mathrm{X}$ & & $\mathrm{X}$ & & $\mathrm{X}$ & & & 3 \\
\hline
\end{tabular}

Figure 2 is describing cellular system architecture with macro cell Base Station and FEMTOCELL, when user is moving from one region to other region the channel allocation can be done from set $\phi \mathrm{n}$. Table 1 is having the channel list assigned to each base station. And allocated channel number also maintained ${ }^{[12][13][14[15]}$. The unused channels can be used for further communication without affecting the primary user.

\section{New Hybrid Channel Allocation algorithm with SFAB}

Channel allocation can be done with the new agile approach by considering the MACRO cell and FEMTOCELL behavior with cognitive principle methods. Many researchers are working on dynamic channel allocation to the secondary user by taking the channels given to primary user if the channel is not occupied ${ }^{[16][17][18][19]}$. The government lease also used effectively if the channels are shared properly. The main mechanism here we are proposing is the coverage should be done at each and every corner of office and house areas. For that the FETMOCELL was kept in the places where primary coverage is not done. So the channel allocation to the user who are under the FEMTOCELL region [20][21][22][23][24]. the users moving from macro cell region to femtocell region and same type of coverage region like FEMTOCELL region to FEMTOCELL region.

Algorithm for channel allocation with agile approach

$\pi €$ Choose the channel which is from 1 to $\mathrm{n}$ with random variable.

$\mathrm{M}^{\leftarrow}$ maxi Ni

$\mathrm{m} \leftarrow \operatorname{mini} \mathrm{Ni}$

selecting $\mathrm{i} \leftarrow \perp \forall \mathrm{i}$

$\operatorname{Ai}(\mathrm{M}+1,0, \mathrm{n}) \subsetneq \perp \forall \mathrm{i}$

// channel allocation logic based on agile approach of Base station region and FEMTOCELL region.

for $\mathrm{j}=\mathrm{M}$ to $\mathrm{m}$ by -1 do

$\mathrm{A}(\mathrm{k}, 0,0) \leftarrow \mathrm{A}(\mathrm{k}+1,0, \mathrm{n}) / /$ channel allocation with updated list

for $\mathrm{p}=1$ to $\mathrm{n}$ do

$$
\begin{aligned}
& \mathrm{A}(\mathrm{j}, 0, \mathrm{p}) \leftarrow \mathrm{A}(\mathrm{j}, 0, \mathrm{p}-1) \\
& \text { if } \mathrm{K} \pi(p)=\mathrm{k} \text { then } \\
& \mathrm{c} \leftarrow \text { AssignChannel(A(j,0,p), } \pi(p)) / / \pi(p)
\end{aligned}
$$

list available with STL

$$
\begin{aligned}
& \qquad \mathrm{A} \pi(p)_{(\mathrm{j}, 0, \mathrm{p}) \leftarrow \mathrm{c}} \\
& \text { Allocation } \pi(p) \leftarrow \mathrm{c} \\
& \text { end if } \\
& \text { end for } \\
& \text { end for }
\end{aligned}
$$

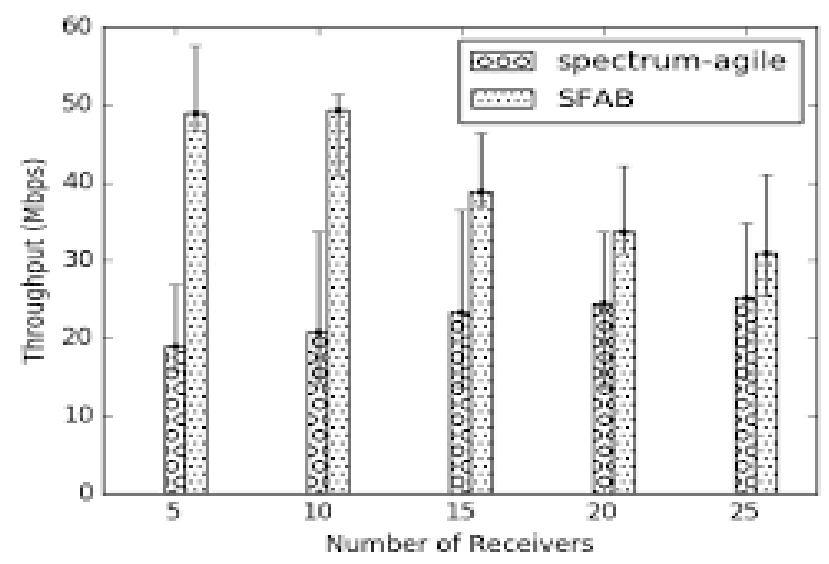


Figure 3: Through put analysis between spectrum-agile Vs SFAB

In Figure 3 compression of throughput (Mbps) was mentioned in cases of spectrum agile approach in wireless communication and Spectrum Fragment Agile Broadcast (SFAB) in wireless cognitive radio networks. With SFAB the data transmission was increased because the channel allocation is done very effectively [25][26][27][28][29][30]. The floated graph is representing that if number of users in random intervals of time and the throughput value of data are measured. For this the data set was taken as user location values and the cellular region coverage in user location $^{[31][32][33][34][35]}$. If Hand Off was handled properly then channel switching for user is more then call drop never happens, next level data packet transmission also will be improved.

In channel allocation algorithm agile approach was used because the channel requirements are going to vary from time to time which can't be fixed. In first line of algorithm a constant value was fixed based on threshold value for channel selection out of $\mathrm{N}$ channels availability. Now select a channel which is 90 degrees to occupied channel. With this cross tier problem also will not happen. Fix the values of $\mathrm{M}$ and $\mathrm{m}$ with max and min value ranges from the available channel list. Select $i^{\text {th }}$ channel based on the 90 degree process, if the channel is not available in the region use the services of FEMTOCELL which is a small base station kept to cover the small region at home or office. Here agile approach will be as iterative method from $i^{\text {th }}$ starting to last range of channels available in the network. Iteration will start from $\mathrm{M}$ i.e. from $\max$ value it's decrements by 1 . It gives the all feasible solutions; out of those best channel will be selected. The channel list will be stored at VRL (visitor Location Register). Based on user need with the SFAB the channel access will be done.

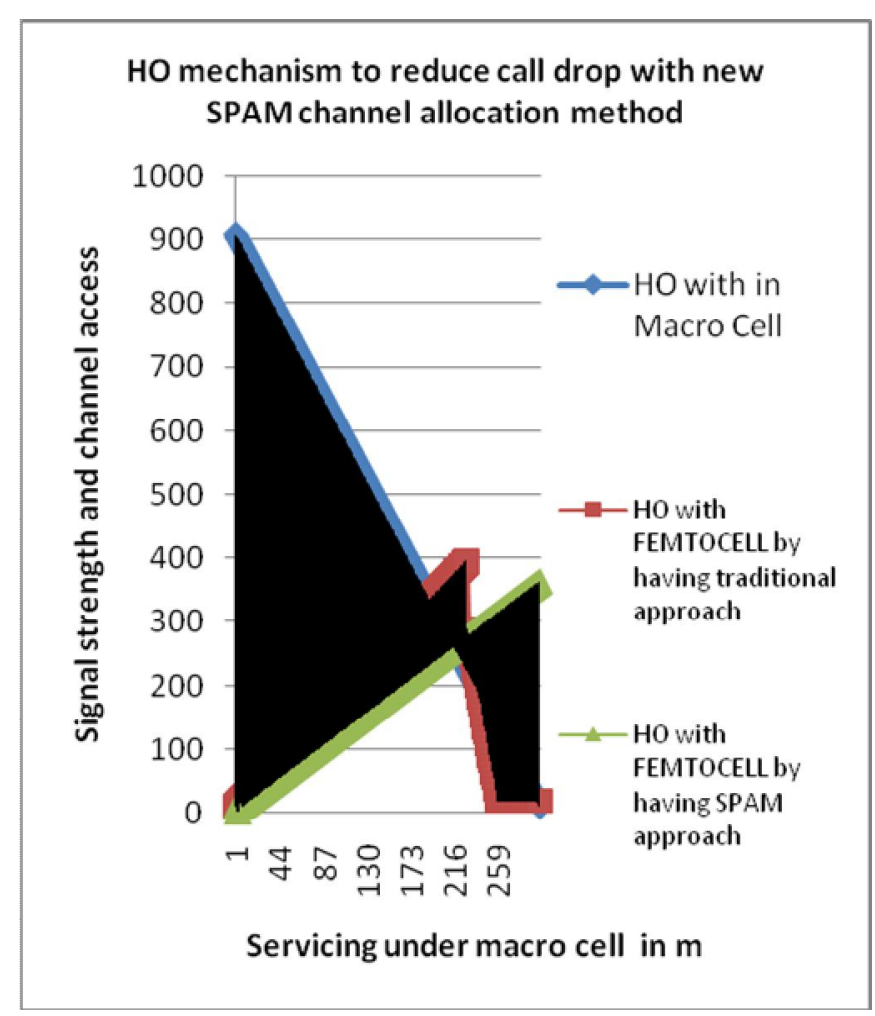

Figure 4: Macro cell Hand Off mechanism in Wireless Communication.

In Figure 4 Hand off $(\mathrm{HO})$ behavior observed graph was plotted at different levels of communication: $\mathrm{HO}$ with in Macro Cell, HO with FEMTOCELL by having traditional approach and HO with FEMTOCELL by having the SPAM approach. The observations are signal strength and channel allocation was increased even though number of users is increased in particular cellular region. Femtocell will take care about the signal coverage issues and new method of SPAM with cognitive approach will give best results for Hand Off mechanism.

\section{CONCLUSION}

The conclusion is that with the traditional method for channel allocation of user equipment in both the macro cell and the femtocell will not work effectively i.e. the quality of service will be achieved but the quality of experience can be achieved by applying the spectrum agile approach with the bucket approach for the channel allocation. Finally the handoff values can be reduces even though the user moves away from macro cell region.

\section{REFERENCES}

1. Haijun Zhang, Chunxiao Jiang,Xiaotao Mao, and Hsiao-Hwa Chen "Interference-Limited Resource optimization in cognitive Femtocells with Fairness and Imperfect Spectrum Sensing” IEEE-2016. 
2. Mahesh Lalapete, Sagr Basavaraju, Navin Kumar “ Performance Analysis of Femtocell on Channel Allocation" Springer-2019.

3. David Lopez-perez, Akos Ladanyi, Alpar Juttner and Jie Zhang "OFDMA femtocells: Intracell Handover for Interference and Handover Mitigation in Two-Tier Networks" IEEE-2010

4. Gdiraju Divija Swetha, Jitendra Grover, Garimella Rama Murty "Dynamic Channel Allocation in Small Cells" ICRITO conference IEEE-2018.

5. Sharada Narsingrao O, Dr Dattatraya S.B "Channel Allocation Technique with Genetic Algorithm for Interference Reduction in cellular Network" IEEE-2013.

6. Anshuman Goel, Mohd. Sheezan, Mumtaz Ahmed "Distributed Dynamic Channel Allocation Scheme in Interference-Limited Sectored Cellular Network" IEEE-2014.

7. R.K. Gosh "Wireless Networking and Data Management" ISBN- 978-981-10-3940-6 Springer-2017.

8. Vasileios kotsiou, Georgios, Z papadopopoulosy, perikilis chatzimisios and fabric theoleyre "Adaptive Multi-channel offset assignment for reliable IEEE 802.15.4 TSCH Networks" IEEE 2018.

9. Yujie Zhang, Shaowel Wang "Resource Allocation for cognitive Radio-Enabled Femtocell Networks with Imperfect Spectrum Sensing and Channel Uncertainty” IEEE 2015.

10. Shree Krishna Sharma, Symeon Chatzinotas, and Bjorn Ottersten "Eigenvalue-Based Sensing and SNR Estimation for Cognitive Radio in Presence of Noise Correlation" IEEE-2013.

11. N. Y. Soltani, S.-J. Kim, and G. B. Giannakis "Chance-constrined optimization of OFDMA cognitive radio uplinks" IEEE Trans.wireless communication vol 12,no.3, pp 1098-1107,Mar.2013

12. Venkata Vara Prasad Padyala, Dr K V D Kiran "Improved handoff mechanism for infiltrating user equipments in composite networks" IJECE Vol. 10, No. 3, pp. 2600 2606 ISSN: 2088-8708, June 2020.

13. Venkata Vara Prasad Padyala, Dr K V D Kiran “ A Prediction Schemme of mobility of cognitive FEMTOCELL LTE-A/LTE_UE under different speed scenarios" IJET, 2018.

14. Guofeng Zhao, Yong Li, Chuan Xu "Joint Power Control and Channel Allocation for Interference Mitigation Based on Reinforcement Learning" IEEE 2019.

15. Chunyi Peng, Yuanjie Li, "Demystify Undesired Handoff in Cellular Networks," 2016 25th International Conference on Computer Communication and Networks (ICCCN), Waikoloa, HI, pp. 1-9, 2016.
16. FENG Lei, YIN Mengjun, XIANG Nan, LI Wenjing, QIU Xuesong, "Load-Balancing Based on Base-Station CoMP with Guaranteed call blocking rate," 2014 International Symposium on Wireless Personal Multimedia Communications (WPMC), Sydney, NSW, pp. 271-276, 2014.

17. Tuan LeAnh, Nguyen H. Tran, "Distributed Power and Channel Allocation for Cognitive Femtocell Network using a Coalitional Game in Partition Form Approach," in IEEE Transactions on Vehicular Technology, vol. 66, no. 4, pp. 3475-3490, Apr. 2017.

18. Gadiparthi, C., Bathina, M., Emani, s, P V Vara Prasad "The spectrum sensing and path optimization techniques in cognitive radionetworks "International Journal of Innovative Technology and Exploring Engineering” 2019

19. Vara Prasad P V , Sowmya N "Introduction to dynamic malware analysis for cyber intelligence and forensics" nternational Journal of Mechanical Engineering and Technology 2018.

20. Ruth Ramya, K Manjula Josephine B, Vara Prasad P $V$ "Pro guard malicious social network account based online promotions open Access" International Journal of Emerging Trends in Engineering Research 2020.

21. Sahu, A. K., \& Swain, G. (2019). A novel n-rightmost bit replacement image steganography technique. 3D Research, 10(1) doi:10.1007/s13319-018-0211-x

22. Sajana, T., \& Narasingarao, M. R. (2019). Majority voting algorithm for diagnosing of imbalanced malaria disease doi:10.1007/978-3-030-00665-5_4 Retrieved from www.scopus.com

23. Bommadevara, H. S. A., Sowmya, Y., \& Pradeepini, G. (2019). Heart disease prediction using machine learning algorithms. International Journal of Innovative Technology and Exploring Engineering, 8(5), 270-272.

24. Raja Sekhar, G. G., \& Banakar, B. (2019). Solar PV fed non-isolated DC-DC converter for BLDC motor drive with speed control. Indonesian Journal of Electrical Engineering and Computer Science, 13(1), 313-323. doi:10.11591/ijeecs.v13.i1.pp313-323

25. Nagendram, S., Madhav, B. T. P., Sony, K., Janaki, P., Lakshmi Prasanna, P., Swetha, S., \& Venkateswara Rao, M. (2018). Study and analysis of single notched rectangular dielectric resonator antenna for cognitive radio applications. 
International Journal of Engineering and Technology(UAE), 7(1.1), 530-533.

26. Suguna, Y. S., Reddy, B. K., Durga, V. K., \& Roshini, A. (2018). Secure quantum key distribution encryption method for efficient data communication in wireless body area sensor net-works. International Journal of Engineering and Technology(UAE), 7(2.32 Special Issue 32), 331-335

27. Guru Prasad, S., Srikanth, K. S., \& Rajanna, B. V. (2018). Advanced active power filter performance for grid integrated hybrid renewable power generation systems. Indonesian Journal of Electrical Engineering and Computer Science, 11(1), 60-73

28. Swain, G. (2018). High capacity image steganography using modified LSB substitution and PVD against pixel difference histogram analysis. Security and Communication Networks, 2018 doi:10.1155/2018/1505896

29. Madhav, B. T. P., Reddy, V. S., Reddy, D. R., Sankar, K. R., Ramanujan, E. V. S. H., Prakash, V. V. S., \& Rao, M. V. (2018). Tree shaped fractal antenna with multiband characteristics. International Journal of Engineering and Technology(UAE),

30. Madhav, B. T. P., Venkateswara Rao, M., \& Anilkumar, T. (2018). Conformal band notched circular monopole antenna loaded with split ring resonator. Wireless Personal Communications, 103(3), 1965-1976. doi:10.1007/s11277-018-5890-3

31. Madhav, B. T. P., Venkateswara Rao, M., Manisahithi, K., Sarvani, D. S. S., Dharani, M., \&
Rami Reddy, S. V. (2018). Compact metamaterial inspired periwinkle shaped fractal antenna for multiband applications. International Journal of Engineering and Technology(UAE), 7(1.1), 507-512.

32. Madhav, B., Dheeraj, G. S., \& Raghavarapu, S. S. (2018). Multiple band mobile antenna for LTE, GSM, PCS, UMTS \& IoT applications. International Journal of Engineering and Technology(UAE), 7(3.27 Special Issue 27), 609-612.

33. Vijayakumar Ponnusamy , T. Karthick, , R. Nandakumar, Yuvaraj "Data-Driven Methods for Next Generation of Wireless Communication Networks" International Journal of Advanced Trends in Computer Science and Engineering , volume 9, No.4, July-august 2020.

34. Nagarjuna Karyemsetty , K Raja Kumar "Comparative Analysis of DSRC and 5G Technologies for Vehicular Communications" International Journal of Advanced Trends in Computer Science and Engineering, volume 9, No.4, July-august 2020.

35. Seong Cheol Kim, Hye Yun Kim "A Traffic Aware and Superframe Adjustment MAC Protocol for Wireless Sensor Networks" International Journal of Advanced Trends in Computer Science and Engineering, volume 9, No.4, July-august 2020. 